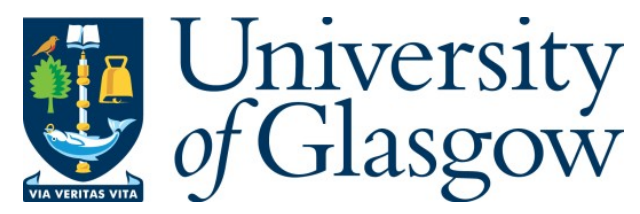

Rashad, M., Minhas, D. M., Ashraf, M., and Hussain, S. (2016) PFC Topologies for AC to DC Converters in DC Micro-Grid. In: 18th Mediterranean Electrotechnical Conference (MELECON), Limassol, Cyprus, 18-20 Apr 2016, ISBN 9781509000586.

There may be differences between this version and the published version. You are advised to consult the publisher's version if you wish to cite from it.

(C) 2016 IEEE. Personal use of this material is permitted. Permission from IEEE must be obtained for all other users, including reprinting/ republishing this material for advertising or promotional purposes, creating new collective works for resale or redistribution to servers or lists, or reuse of any copyrighted components of this work in other works.

http://eprints.gla.ac.uk/123543/

Deposited on: 06 October 2016

Enlighten - Research publications by members of the University of Glasgow http://eprints.gla.ac.uk 


\title{
PFC Topologies for AC to DC Converters in DC Micro-Grid
}

\author{
Muhammad Rashad $^{1}$, Daud Mustafa Minhas ${ }^{1,2}$, Muhammad Ashraf ${ }^{2}$ and Sajjad Hussain ${ }^{2}$ \\ ${ }^{1}$ Department of Electrical Engineering, The University of Lahore, Pakistan \\ ${ }^{2}$ Department of Electrical Engineering, Capital University of Science and Technology, Pakistan
}

\begin{abstract}
With increasing dominance of renewable energy resources and DC household appliances, the novelty of DC micro grid is attracting significant attention. The key interface between the main supply grid and DC micro grid is $\mathrm{AC}$ to $\mathrm{DC}$ converter. The conventional AC to DC converter with large output capacitor introduces undesirable power quality problems in the main supply current. It reduces system efficiency due to low power factor and high harmonic distortion. Power Factor Correction (PFC) circuits are used to make supply currents sinusoidal and in-phase with supply voltages. This paper presents different PFC topologies for single phase AC to DC converters which are analyzed for power factor (PF), total harmonic distortion (THD) and system efficiency by varying output power. Two-quadrant shunt active filter topology attains a power factor of $0.999,3.03 \%$ THD and $98 \%$ system efficiency. Output voltage regulation of the presented active PFC topologies is simulated by applying a step load. Two-quadrant shunt active filter achieves better output voltage regulation compared to other topologies and can be used as grid interface.
\end{abstract}

Keywords- Power Factor Correction, Two-Quadrant Shunt Active filter, Voltage Regulation component

\section{INTRODUCTION}

With the growing awareness of DC renewable energy in distribution schemes and fast evolution of DC loads, DC micro grids are looking more attractive due to their ability to efficiently integrate DC loads with renewable DC sources. [15]. The prototype shift from AC to DC distribution system enables the relaxed control of individual load and easier interface of renewable energy sources with energy storage and main supply grid $[2,6]$.

DC micro grids are becoming popular in the residential complexes [7] and commercial buildings [8]. The benefits of DC micro grids are summarized as follows:

1. DC micro grid gains higher system efficiency due to reduced DC to AC conversion losses $[9,10]$.

2. In DC micro grids, there is no requirement of frequency synchronization and reactive power compensation.

3. When a voltage dip occurs in main supply grid, DC bus voltage is not directly affected due to the presence of energy storage devices.

There remain certain problems in putting DC micro grids into practice which are:
1. DC grid requires the installation of new DC distribution lines.

2. Protection in DC micro grid turns out to be difficult because there is no zero crossing of the voltage in DC distribution system.

There are two modes of operation in DC micro grid; standalone mode and grid connected mode as discussed in literature [3-6]. In the grid connected mode, AC to DC grid interface is required to satisfy the deficit power requirements of the micro grid. This paper presents the different PFC topologies to rectify the problems generated by the conventional AC to DC grid interface in the grid connected mode.

Conventional AC to DC grid interface with bulky output capacitor draws high current pulses from the main supply grid which results in increased harmonic distortion and reduced power factor. PFC stage is required with the conventional $\mathrm{AC}$ to DC grid interface to improve the power factor of the main supply grid. Different passive and active PFC topologies have been presented in the literature [11-17]. In most of the literature, the performance parameters (PF, THD and system efficiency) of PFC topologies are analyzed for the AC to DC power supply applications. These topologies are not discussed in literature for DC micro grid applications.

In this paper, different passive and active PFC topologies are presented for single phase AC to DC converter. The main focus in this work is to analyze PFC topologies for the application of interfacing main supply grid with DC micro grid. PF, THD and system efficiency of the presented topologies are simulated in MATLAB/Simulink against the variation in output power. DC bus voltage stability of the PFC topologies is analyzed by applying a step load. Comparison of the discussed topologies is also presented.

\section{A. DC grid architecture}

DC micro grids are gaining attention with the increasing demand of solar energy and DC loads. DC micro grids are better suited for the integration of energy storage, DC loads and energy sources because most of the power available from renewable energy sources is DC [1-5]. Fig. 1 shows the architecture of the DC micro grid. DC loads, batteries and AC loads can be interfaced to the DC bus through DC to DC and $\mathrm{DC}$ to $\mathrm{AC}$ converters. Whereas main supply grid can be interfaced using $\mathrm{AC}$ to $\mathrm{DC}$ converter. 


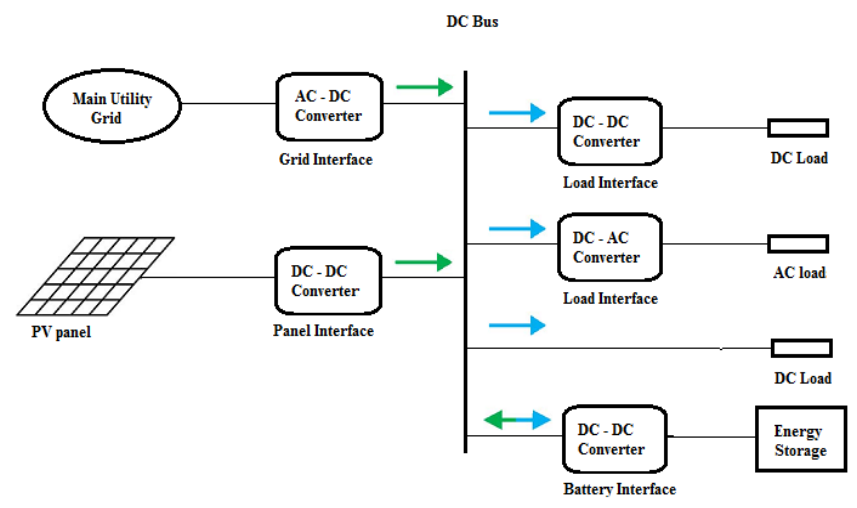

Fig. 1. Architecture of the DC micro grid

\section{B. Conventional AC to DC converter}

The behavior of a single phase AC to DC converter, which is primarily used as gird interface, is nonlinear. The conventional single phase AC to DC converter consists of a full bridge rectifier with capacitor connected at output as shown in Fig. 2.

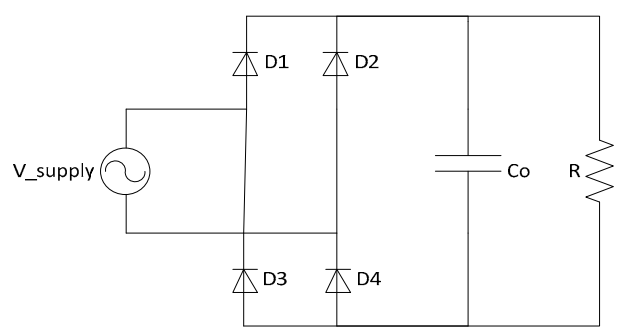

Fig. 2. Single phase AC to DC converter

Output capacitor in AC to DC converter is generally used to reduce output voltage ripples [18]. This conventional AC to DC converter introduces impulsive characteristics into the supply current, resulting in a high THD and low power factor [19]. Another possibility for the occurrence of nonlinear behavior of the AC to DC converter arises when it is connected with an output inductor. The addition of an inductor at output results in the peak reduction of the supply current and power factor perfection. However, two problems must be considered in this case: large inductor size and probable resonance among the output inductor and capacitor [19]. Thus $\mathrm{AC}$ to $\mathrm{DC}$ converter can operate in the continuous current conduction mode (CCM) where the output inductor current never approaches zero and hence, the AC to DC converter is continuously in conducting state. On the other hand, discontinuous conduction mode (DCM) occurs when the output inductor current reaches zero for a specific period of time. The CCM and DCM are discussed in [19].

\section{PFC TOPOLOGIES}

Power factor correcting stage is required for the interfacing of main supply grid with DC micro grid in order to improve power factor and reduce distortion in the supply current. Various passive and active PFC topologies are used to improve power factor as discussed below.

\section{A. Passive PFC Topologies}

Simplest way to improve power factor involves passive techniques. Passive PFC topologies use reactive elements inductor and capacitor to improve power factor. There are different passive PFC topologies discussed in literature [14, 20]. Passive PFC topologies presented in this paper are discussed below.

1) Converter with supply side inductor: A simple PFC method is to add an inductor in series with the supply voltage of the conventional AC to DC converter as shown in Fig. 3.

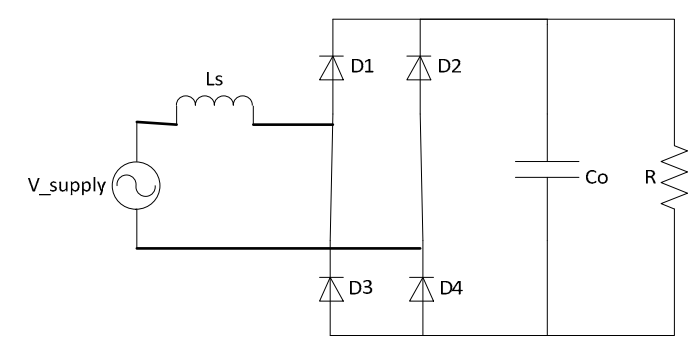

Fig. 3. Converter with supply side inductor

2) Converter with output side inductor: An inductor is added at the output of the conventional AC to DC converter as shown in the Fig. 4. For the large value of the inductor, the inductor current becomes constant and the supply current of the AC to DC converter becomes square shaped. For small inductor value, the output inductor current becomes discontinuous. This can be improved by connecting a capacitor to the supply side as shown in Fig. 4. The advantage of connecting supply side capacitor is that it reduces the size of the output inductor.

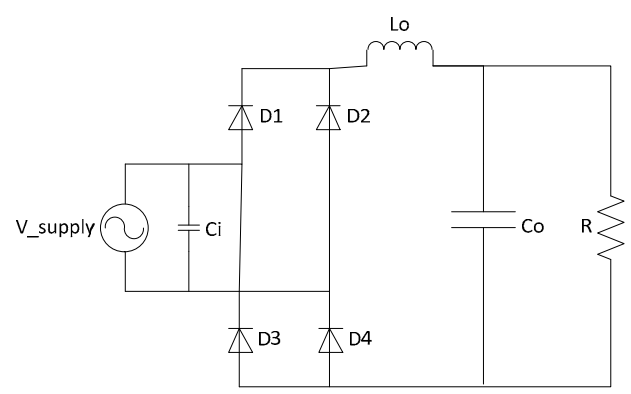

Fig. 4. Converter with output side inductor

3) Converter with series resonant filter: The shape of the supply current wave can be further improved by introducing a series resonant filter (tuned at line frequency) as shown in Fig. 5. But at line frequency, bulky values of reactive components are required.

4) Converter with parallel resonant filter: Another possible configuration is to introduce parallel resonant filter as shown in Fig. 6. Parallel resonance filter can be tuned at third harmonic thereby lowering the values of reactive components as compared to the series resonant filter. 


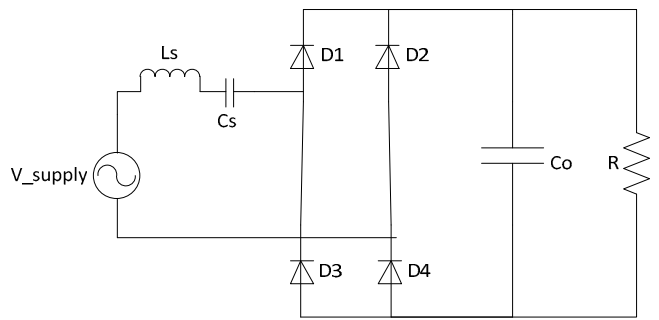

Fig. 5. Converter with series resonant filter

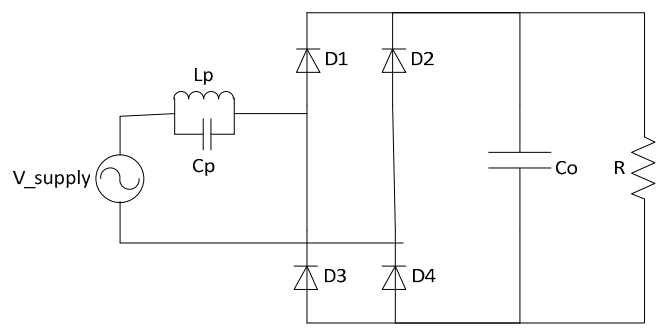

Fig. 6. Converter with parallel resonant filter

As the system operating frequency is low, passive PFC topologies require high powered inductors and capacitors which are expensive and bulky and have low dynamic response. This makes passive PFC topologies less attractive for use in power factor correction circuits.

\section{B. Active PFC Topologies}

Active power factor correction involves semiconductor switches in combination with smaller passive elements that make the supply current sinusoidal and in-phase with the supply voltage to improve the power factor. In addition, it provides output voltage regulation by changing the duty cycle of the active switches. This is an efficient way to deliver electrical power to the consumers by power supplying companies. Wide input voltage range and output voltage regulation make the active $\mathrm{PFC}$ attractive for many power suppliers.

There are different active PFC topologies presented in the literature [11-14]. Active PFC topologies presented in this paper for the above mentioned DC micro grid are given below.

1) $A C$ to $D C$ fly-back converter: It is a buck-boost style converter with the inductor divided to form a transformer. AC to DC fly-back converter is shown in Fig. 7. Transformer in the fly back converter acts as an inductor as only one coil conducts at a time.

2) Converter with quasi active power factor correction $(Q A P F C)$ : This topology improves the power factor by adding an extra coil to the transformer of AC to DC fly-back converter. The extra coil is placed between the AC to DC rectifier and filter capacitor in order to serve as a magnetic switch to derive an input inductor as shown in Fig. 8. [23].

3) Converter with phase-shifted semi bridgeless PFC: This topology introduces two extra diodes $D_{a}$ and $D_{b}$ to the bridgeless PFC topology as shown in Fig. 9. The current does not always return through these extra diodes, so conduction losses associated with them are low. Details of semi bridgeless converter are presented in [24].

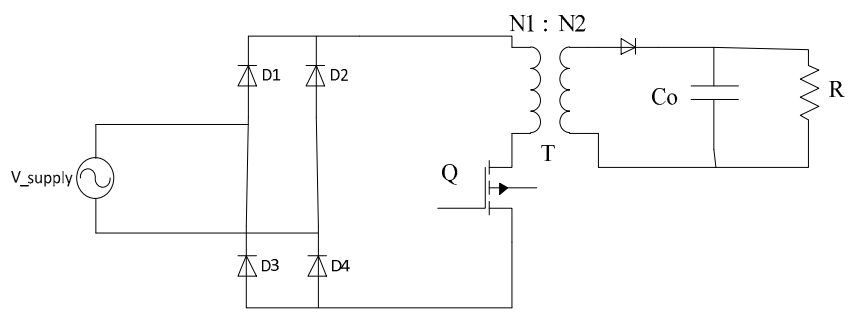

Fig. 7. AC to DC fly-back converter

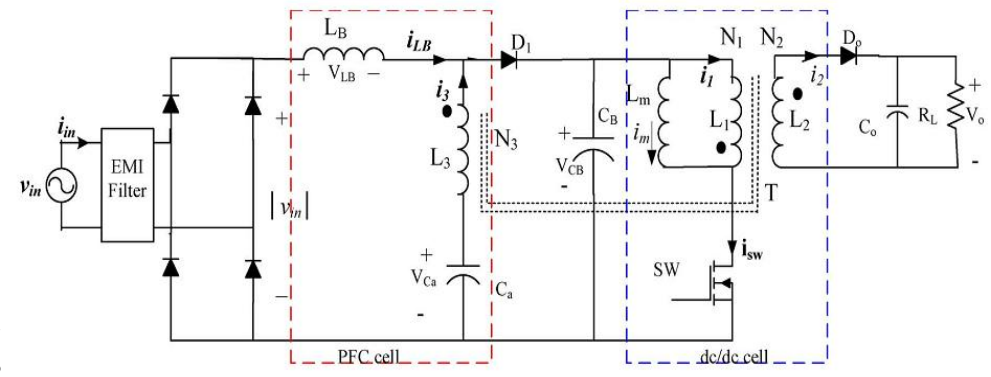

Fig. 8. Quasi active power factor correction [23]

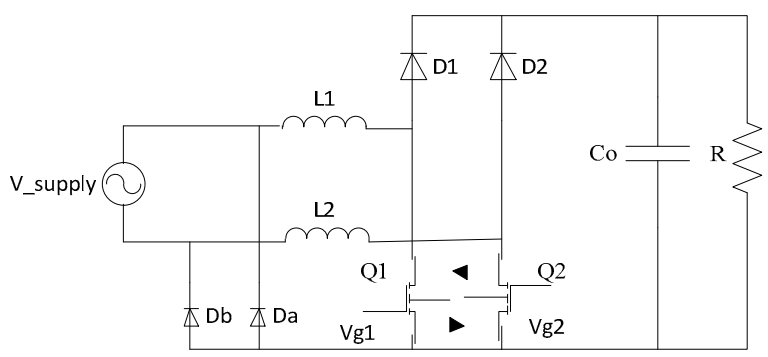

Fig. 9. Phase-shifted semi bridgeless PFC [24]

4) Converter with two-quadrant shunt active filter: This topology consists of a bidirectional DC to DC converter and is connected at the DC side of the AC to DC converter followed by an inductive filter [22]. Fig. 10 shows the twoquadrant shunt active filter structure with its control strategy.

The detailed operation of the two-quadrant shunt active filter is discussed in [18] [22]. $\mathrm{F}_{\mathrm{N}}(\mathrm{s})$ in control strategy of Fig. 10 is a band stop filter which is used to filter out the inductor capacitor load resonance. $\mathrm{K}_{\mathrm{I} 0}$ is current gain, $\mathrm{C}_{\mathrm{i}}(\mathrm{s})$ and $\mathrm{C}_{\mathrm{V}}(\mathrm{s})$ are proportional integral controller with filter.

\section{SimUlATION RESULTS}

Simulations of different PFC topologies using MATLAB is presented below. Conventional AC to DC converter is simulated for $220 \mathrm{~V}_{\mathrm{rms}}$ supply voltage, $50 \mathrm{~Hz}$ frequency and variable load. Simulated supply voltage and current waveforms of conventional single phase AC to DC converter are shown in Fig. 11. Scaled supply voltage is shown in Fig. 11(a). Fig. 11(b) shows the impulsive behavior of the supply 
current with resistive load. This shows that output capacitor takes huge charge during short portion of a cycle and discharges the energy to the load until the beginning of the next cycle. The supply current in this case is discontinuous with a power factor of 0.48. Fig. 11(c) shows the supply current for CCM and Fig. 11(d) shows the supply current for DCM.

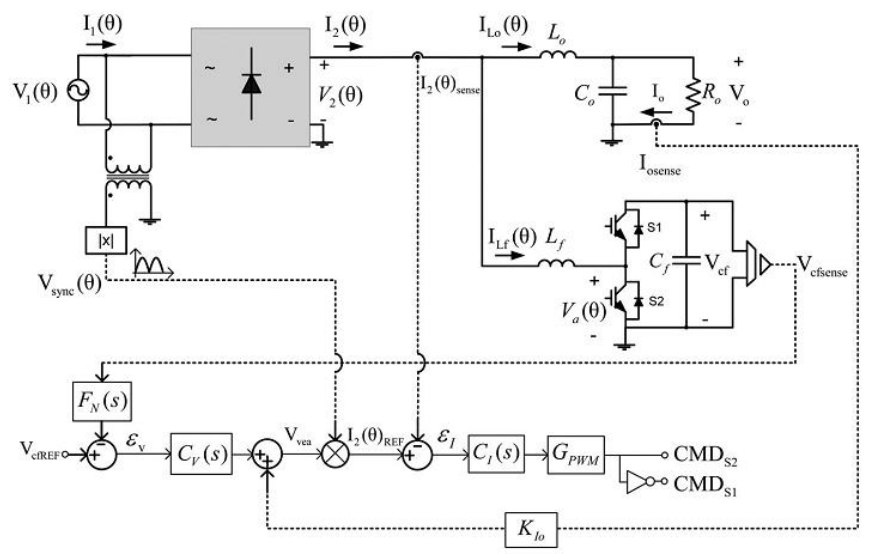

Fig. 10. Two quadrant shunt active filter with input current control [18]
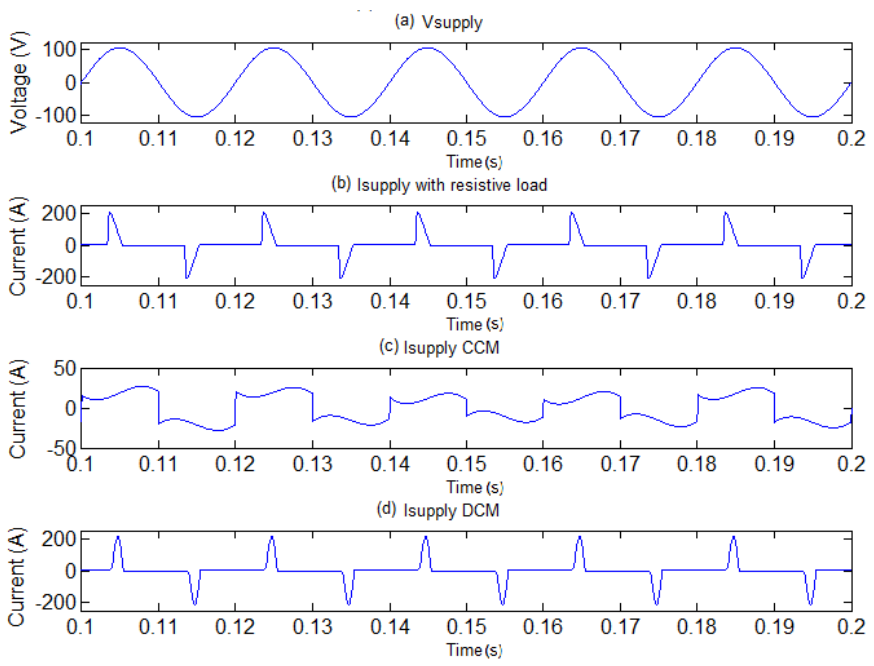

Fig. 11. Supply voltage and current waveforms of conventional AC to DC converter

Passive PFC topologies presented in this paper are simulated and shown in Fig. 12. Scaled supply voltage is shown in Fig. 12(a). Fig. 12(b) shows the supply current for the converter with supply side inductor. Fig. 12(c) shows the supply current for converter with output side inductor (with and without input side capacitor). Fig 12(d) and 12(e) show the supply current for converter with series and parallel resonance filters. Maximum PF achieved is 0.76, 0.89, 0.98 and 0.95 for converter with supply side inductor, output side inductor, series and parallel resonance respectively.

PF, THD and system efficiency of the presented PFC topologies are plotted against varying output power as shown in Fig. 13, 14 and 15 respectively. These plots show that as output power increases, PF and system efficiency for the converter with supply side and output side inductor decreases.
The minimum value of THD with supply side and output side inductor is observed to be $12.31 \%$ and $42.69 \%$ respectively, whereas the maximum percentage of system efficiency achieved is $76 \%$ and $89 \%$ respectively.
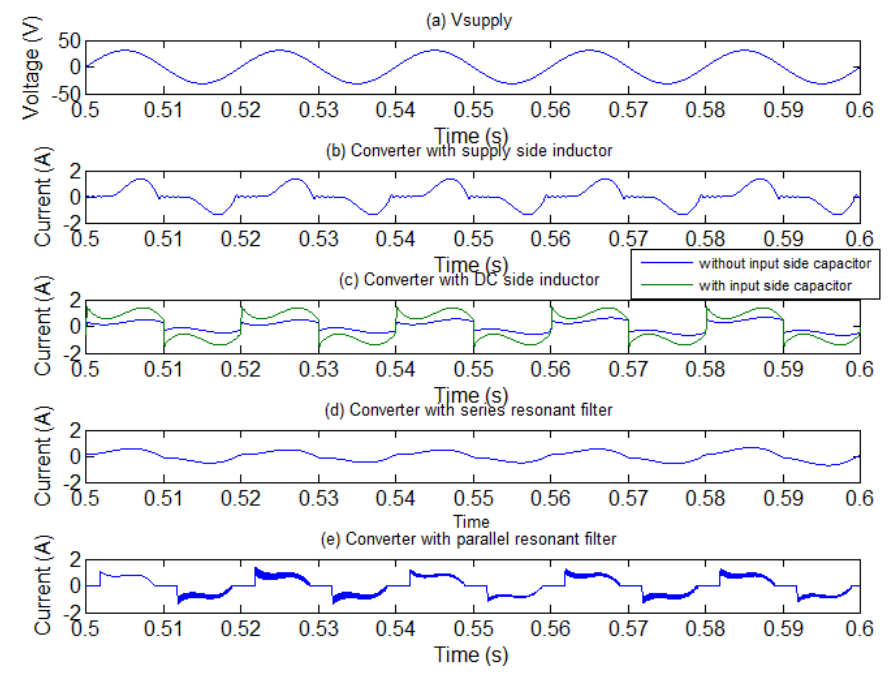

Fig. 12. Supply voltage and current waveforms with passive PFC topologies

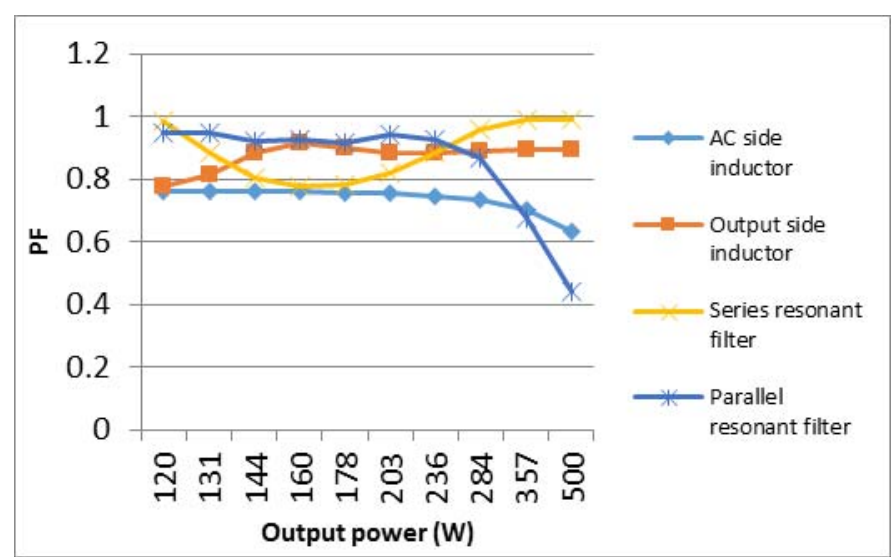

Fig. 13. PF with passive PFC topologies

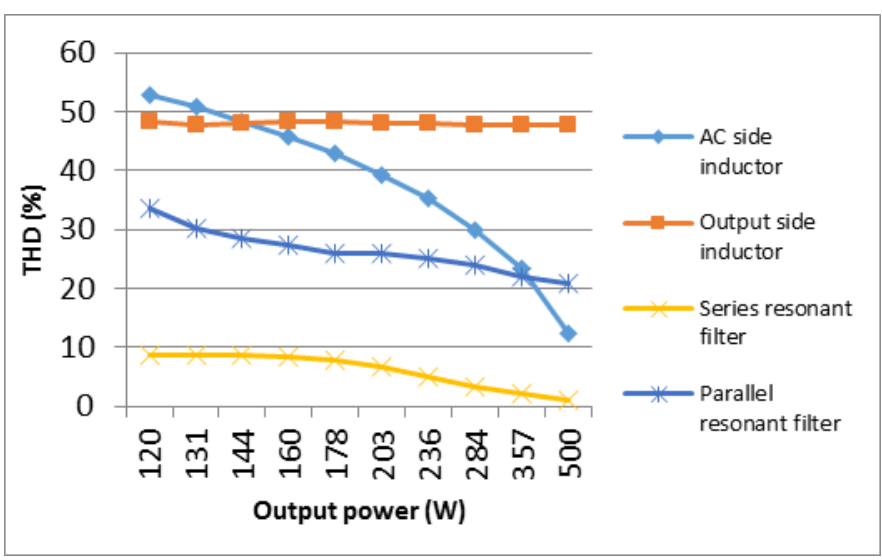

Fig. 14. THD with passive PFC topologies 


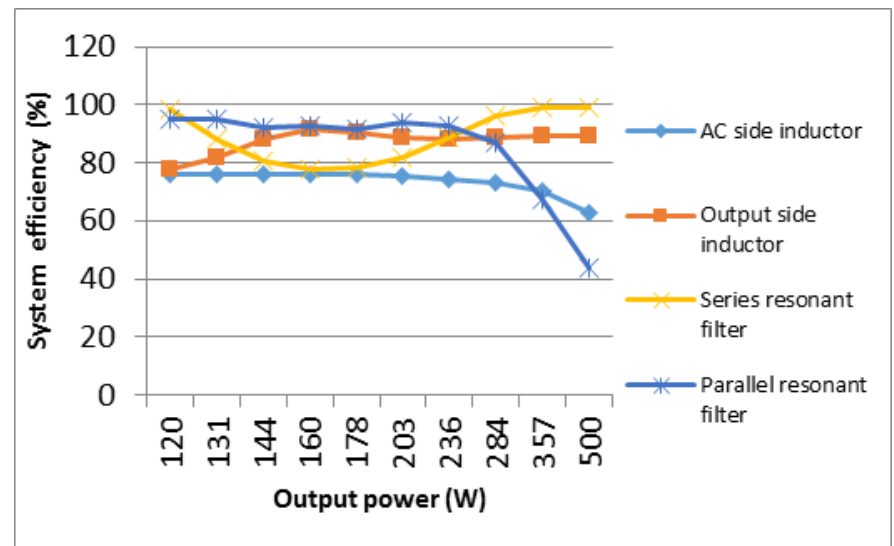

Fig. 15. System efficiency with passive PFC topologies

Active PFC topologies presented in this paper are simulated and shown in Fig. 16. Scaled supply voltage is shown in Fig. 16(a). Fig. 16(b) shows the supply current for AC to DC fly-back converter. Fig. 16(c) shows the supply current for quasi APFC. Fig. 16(d) shows the supply current for phase-shifted semi bridgeless PFC. Fig. 16(e) shows the supply current for two-quadrant shunt active filter. Maximum $\mathrm{PF}$ achieved is $0.93,0.95,0.92$ and 0.99 for $\mathrm{AC}$ to DC flyback converter, QAPFC, phase-shifted semi bridgeless PFC and two-quadrant shunt active filter respectively.
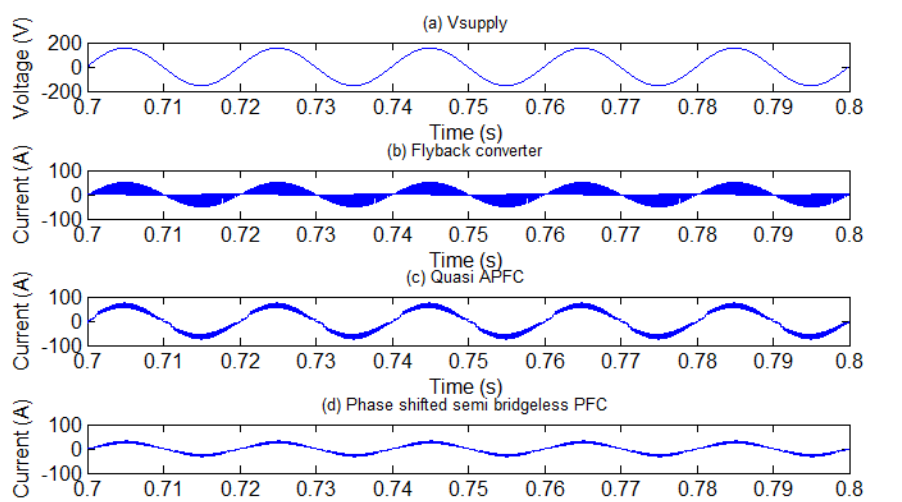

$\begin{array}{ll}\text { Time (s) } & \text { (e) Two quadrant shunt active filter }\end{array}$

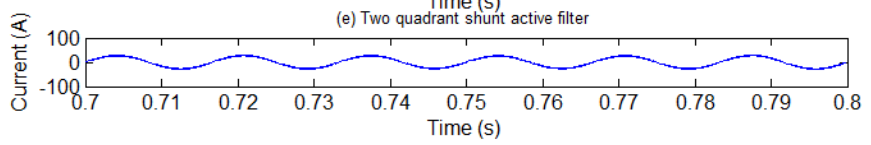

Fig. 16. Supply voltage and current waveforms with active PFC topologies

PF, THD and system efficiency of the simulated active PFC topologies are plotted against varying output power as shown in Fig. 17, 18 and 19 respectively. It shows that increasing output power does not create significant variation in these parameters for the fly-back converter and QAPFC. In phase-shifted semi bridgeless topology, PF decreases and THD increases with the increase in output power.

The minimum value of THD with fly-back converter, QAPC, phase-shifted semi bridgeless PFC and two-quadrant shunt active filter is observed to be $25.1 \%, 14.4 \%, 11.28 \%$ and $3 \%$ respectively, whereas the maximum percentage of system efficiency achieved is $95.6 \%, 81 \%, 93 \%$ and $98 \%$ respectively.

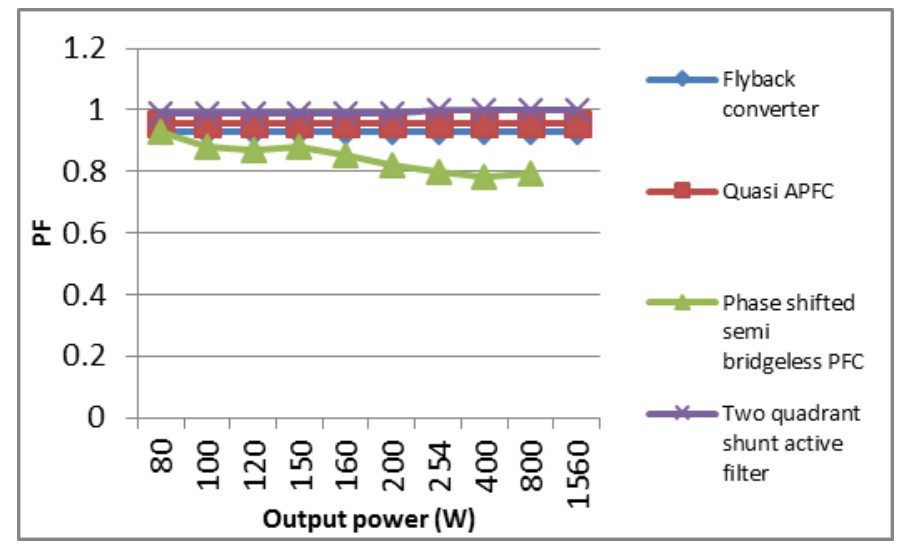

Fig. 17. PF with active PFC topologies

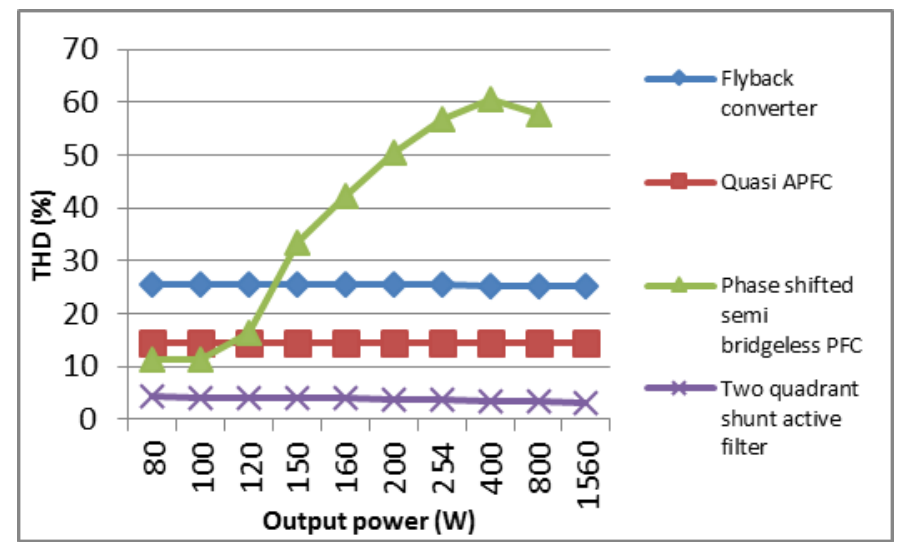

Fig. 18. THD with active PFC topologies

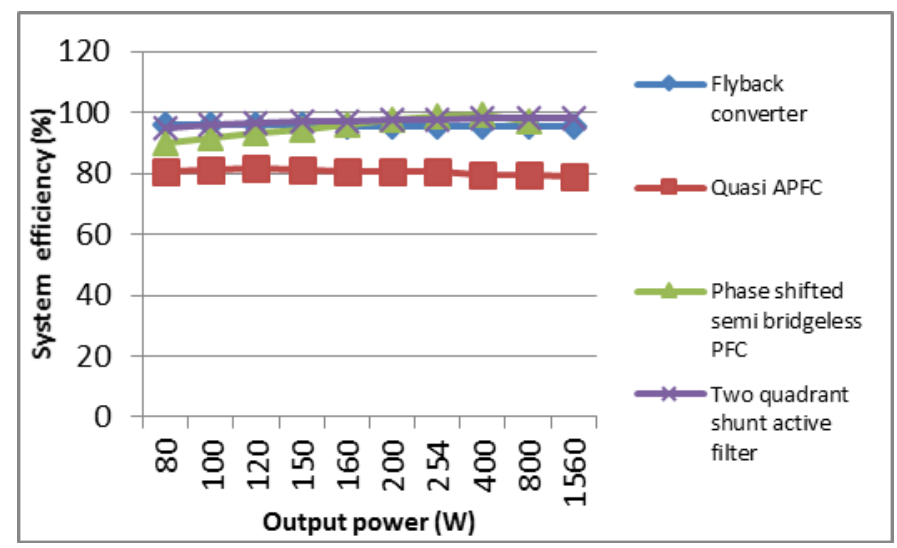

Fig. 19: System efficiency with active PFC topologies

A step load is applied at the bus of DC micro grid to analyze the voltage stability of the active PFC topologies presented. Fig. 20 shows the DC bus voltage of converter with active PFC topologies when a step load is applied at 0.9 seconds. Fig. 20(a) shows that high oscillations are observed in the fly-back converter. Fig. 20(b) shows that voltage sag is produced in converter with QAPFC. Fig. 20(c) shows that both voltage sag and oscillations are seen in phase-shifted semi bridgeless PFC. However in two-quadrant shunt active filter, oscillations are produced but are damped out at 1.6 seconds as shown in Fig. 20(d). 
Fly-back converter, quasi APFC and phase-shifted semi bridgeless PFC are open loop topologies in which voltage regulation cannot be achieved for varying load. Whereas twoquadrant shunt active filter achieved better output voltage and current regulation. So it is the best of all PFC topologies analyzed for the $\mathrm{AC}$ to $\mathrm{DC}$ converter for grid interfacing.

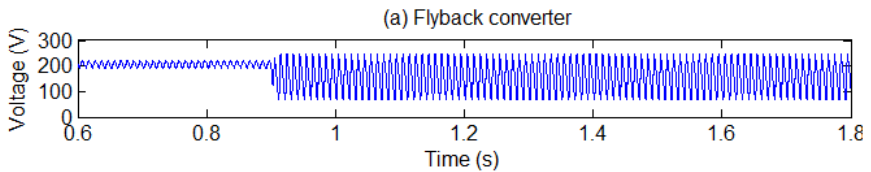

(b) Quasi APFC

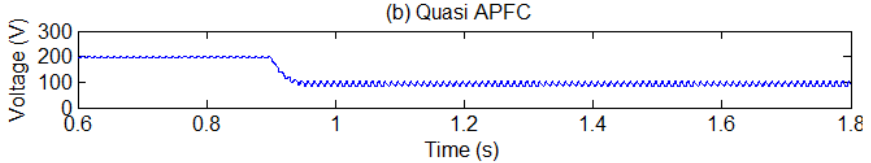

(c) Phase shifted semi bridgeless PFC

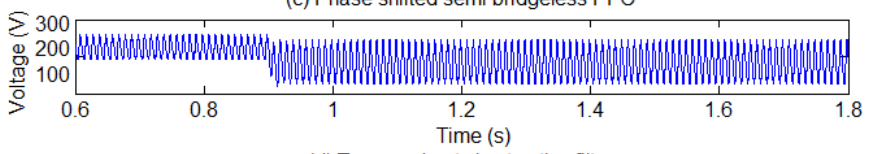

(d) Two quadrant shunt active filter

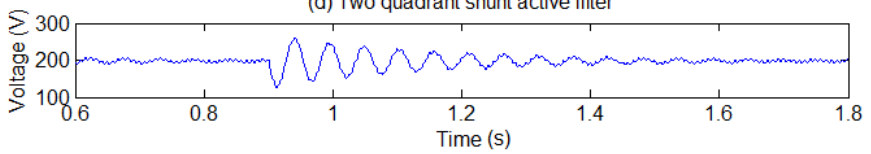

Fig. 20: DC bus voltage with active PFC topologies when a step load is applied at 0.9 seconds

\section{CONCLUSION}

With increasing number of DC household appliances and growing dependence on DC power from renewable energy resources the DC micro grids are gaining popularity. The key interface between the main supply grid and DC micro grid is $\mathrm{AC}$ to DC converter. Different passive and active PFC topologies for $\mathrm{AC}$ to $\mathrm{DC}$ converter interface have been presented and analyzed for PF, THD and system efficiency with variation in output power.

Two-quadrant shunt active filter, compared to other topologies presented, is a feedback controlled topology, which attains better output voltage regulation on a step load. It attains maximum PF of 0.999 , THD $3.03 \%$ and system efficiency $98 \%$. The supply current of two-quadrant shunt active filter is sinusoidal with less distortion. This topology can be used to interface main supply grid with the DC micro grid.

\section{REFERENCES}

[1] Chi Jin, Peng Wang, Jianfang Xiao, Yi Tang and Fook Hoong Choo, "Implementation of hierarchical control in DC microgrids," IEEE Trans. Industrial Electron., vol. 61, no. 8, pp. 4032-4042, Aug. 2014.

[2] Sandeep Anand, Baylon G. Fernandes and Josep M. Guerrero, "Distributed control to ensure proportional load sharing and improve voltage regulation in low-voltage DC microgrids," IEEE Trans. Power Electron., vol. 28, no. 4, pp. 1900-1913, Apr. 2013.

[3] X. Liu, P. Wang, and P. C. Loh, "A hybrid AC/DC microgrid and its coordination control," IEEE Trans. Smart Grid, vol. 2, no. 2, pp. 278286, Jun. 2011.

[4] J. M. Guerrero, J. C. Vasquez, J. Matas, L. G. de Vicuna, and M. Castilla,"Hierarchical control of droop-controlled AC and DC microgrids, A general approach toward standardization," IEEE Trans. Ind. Electron., vol. 58, no. 1, pp. 158-172, Jan. 2011.
[5] H. Kakigano, Y. Miura, and T. Ise, "Low-voltage bipolar-type dc microgrid for super high quality distribution," IEEE Trans. Power Electron., vol. 25, no. 12, pp. 3066-3075, Dec. 2010.

[6] J. M. Guerrero, L. Poh Chiang, L. Tzung-Lin, and M. Chandorkar, "Advanced control architectures for intelligent microgrids-Part II: Power quality, energy storage, and AC/DC microgrids," IEEE Trans. Ind. Electron., vol. 60, no. 4, pp. 1263-1270, Apr. 2013.

[7] D. Salomonsson, L. Soder, and A. Sannino, "An adaptive control system for a dc microgrid for data centers," IEEE Trans. Ind. Appl., vol. 44, no. 6, pp. 1910-1917, Nov./Dec. 2008.

[8] A. Sannino, G. Postiglione, and M. H. J. Bollen, "Feasibility of a dc network for commercial facilities," IEEE Trans. Ind. Appl., vol. 39, no. 5, pp. 1499-1507, Sep./Oct. 2003.

[9] H. Kakigano, M. Nomura, and T. Ise, "Loss evaluation of DC distribution for residential houses compared with AC system," in Proc. Int. Power Electron. Conf. (IPEC)-ECCE Asia, Sapporo, Japan, 2010, pp. $480-486$.

[10] Y. Ito, Y. Zhongqing, and H. Akagi, "DC microgrid based distribution power generation system," in Proc. IEEE 4th Int. Power Electron. Motion Control Conf. (IPEMC), vol. 3, 2004, pp. 1740-1745.

[11] A. R. Prasad, P. D. Ziogas, and S. Manias, "A novel passive wave shaping method for single-phase diode rectifiers," IEEE Trans. Ind. Electron., vol. 37, no. 6, pp. 521-530, Dec. 1990.

[12] Daniel Tollik and Andrzej Pietkiewicz, "Comparative analysis of 1phase active power factor correction topologies," in Proc. IEEE $14^{\text {th }}$ Int. Telecommunication Energy Conf. (INTELEC), Washington, 1992, pp.517-523.

[13] Yasunobu Suzuki, Toru Teshima, Isao Sugawara and Akira Takeuchi, "Experimental studies on active and passive PFC circuits," in Proc. IEEE $19^{\text {th }}$ Int. Telecommunication Energy Conf. (INTELEC), Melbourne, 1997, pp. 571-578.

[14] Oscar García, José A. Cobos, Roberto Prieto, Pedro Alou and Javier Uceda, "Single Phase Power Factor Correction: A Survey," IEEE Trans. Power Electron., vol. 18, no. 3, pp. 749-755, May 2003.

[15] Werner Hugo Wolfle and William Gerard Hurley, "Quasi-active power factor correction with a variable inductive filter: theory, design and practice," IEEE Trans. Power Electron., vol. 18, no. 1, pp. 248-255, Jan. 2003.

[16] H. A. Kazem, "An improved method of passive input current wave shaping for single-phase rectifier," in Proc. IEEE Compat. Power Electron. Conf. (CPE), Gdansk, 2007, pp. 1-4.

[17] Suma Umesh, L.Venkatesha and Usha A, "Active power factor correction technique for single phase full bridge rectifier," in Proc. IEEE Adv. Energy Conversion Technologies Conf. (ICAECT), Manipal, 2014, pp.130-135.

[18] Silvia Helena Pini and Ivo Barbi, "A single-phase high-power-factor rectifier, based on a two-quadrant shunt active filter," IEEE Trans. Power Electron., vol. 26, no. 11, pp. 3131-3143, Nov. 2011.

[19] Yasunobu Suzuki, Toru Teshima, Isao Sugawara, Akira Takeuchi, "Experimental Studies on Active and Passive PFC Circuits," in Proc. IEEE $19^{\text {th }}$ Int. Telecommunication Energy Conf. (INTELEC), Melbourne, 1997, pp. 571-578.

[20] Ned Mohan, Tore M. Undeland, William P. Robbins, "Power Electronics Converters, Applications and design," John Wiley and sons, Inc., 2003, ch. 6, pp. 77-120.

[21] Muhammad H. Rashid, "Power Electronics Circuits, Devices and Applications," $3^{\text {rd }}$ ed., Prentice Hall Intl, 2007, ch.3, pp. 68-121.

[22] S. H. Pini, "Study and implementation of a two-quadrant shunt active power filter connected on the DC side of a rectifier with inductor filter," (in Portuguese), Master's dissertation, Power Electron. Inst., Federal Univ. Santa Catarina, Florian'opolis, Brazil, 2010.

[23] Hussain S. Athab, Dylan Dah-Chuan Lu, "A high efficiency AC/DC converter with quasi active power factor correction," IEEE Trans. Power Electron., vol. 25, no. 5, pp. 1103-1109, May 2010.

[24] Wilson Eberle and William G. Dunford, "A phase shifted semibridgeless boost power factor corrected converter for plug in hybrid electric vehicle battery chargers," in Proc. IEEE 26 ${ }^{\text {th }}$ Annual Applied Power Electron. Conf. (APEC), Fort Worth, 2011, pp. 821-828. 